\title{
New surgical method of chordal replacement for mitral valve incompetence with echocardiographic guidance
}

\author{
An experimental study
}

Chordal replacement with expanded polytetrafluoroethylene suture has become a procedure of choice for repairing anterior leaflet prolapse among certain surgeons. However, most surgeons believe that the chordal replacement is too complicated and not reproducible. This report introduces a new method of chordal replacement using intraoperative epicardial and transesophageal echocardiography. Three dogs underwent the following procedures. One major marginal chorda of an anterior mitral leaflet was resected during cardiopulmonary bypass. A specially designed 3-0 polytetrafluoroethylene suture, having straight needles, was attached to the anterior leaflet by a mattress suture. Then the needles were brought from the root of the anterior papillary muscle to the outside of the left ventricle. After the bypass flow was reduced, both ends of the polytetrafluoroethylene suture were pulled under echocardiographic guidance until valve competence was achieved. At that point, the suture was temporarily tied. When cardiopulmonary bypass was discontinued, competence was again confirmed and the suture was tied permanently. When the procedures were completed, echocardiography showed trivial regurgitation and good pliability of the anterior leaflets in all animals. Left atrial pressures were sufficiently decreased. It appears that this new technique is reproducible for all surgeons because the optimal length of polytetrafluoroethylene chordae is determined with the valve functioning. (J THORAC CARDIOVASC SURG 1994;108:719-26)

Takatsugu Shimono, MD, Hiroshi Yuasa, MD, Toru Mizumoto, MD,

Katsumoto Hatanaka, MD, Hitoshi Kusagawa, MD, and Isao Yada, MD, Tsu, Japan

$\mathrm{S}$ of chordal replacement of the mitral valve with expanded polytetrafluoroethylene (PTFE) sutures, many reports have advocated the usefulness of PTFE sutures and the good results of chordal replacement for mitral valve incompetence. ${ }^{2-5}$ Recently, replacement of chordae tendineae with PTFE suture has become the procedure of choice for repairing anterior leaflet prolapse among cer-

From the Department of Thoracic and Cardiovascular Surgery, Mie University, School of Medicine, Tsu, Japan.

Received for publication Jan. 28, 1994.

Accepted for publication May 10, 1994.

Address for reprints: Takatsugu Shimono, MD, Department of Surgery, Baylor College of Medicine, One Baylor Plaza, Houston, TX 77030 .

Copyright 1994 by Mosby-Year Book, Inc.

$0022-5223 / 94 \$ 3.00+0 \quad \mathbf{1 2} / \mathbf{1} / \mathbf{5 7 5 8 3}$ tain surgeons. ${ }^{4-6}$ However, many surgeons believe that replacement of chordae tendineae is complicated and not reproducible. The major problem is how to decide an optimal length of new tendons. Therefore, we tried to develop a new method of chordal replacement for mitral incompetence, using intraoperative echocardiography, in which a specially designed PTFE suture with straight needles was used. This report describes a preliminary animal study of this new surgical technique.

\section{Material and methods}

Three adult mongrel dogs, weighing $15 \mathrm{~kg}, 16 \mathrm{~kg}$, and $17 \mathrm{~kg}$, were used for this study and underwent the same procedures. All animals were treated and operated on in accordance with the "Guide for the Care and Use of Laboratory Animals" published by the National Institutes of Health (NIH publication No. 86-23, revised 1985). The three dogs were anesthetized with intravenous injections of pentobarbital $(25 \mathrm{mg} / \mathrm{kg})$ and pancuronium $(0.08 \mathrm{mg} / \mathrm{kg})$, and they were intubated. Anesthesia was 


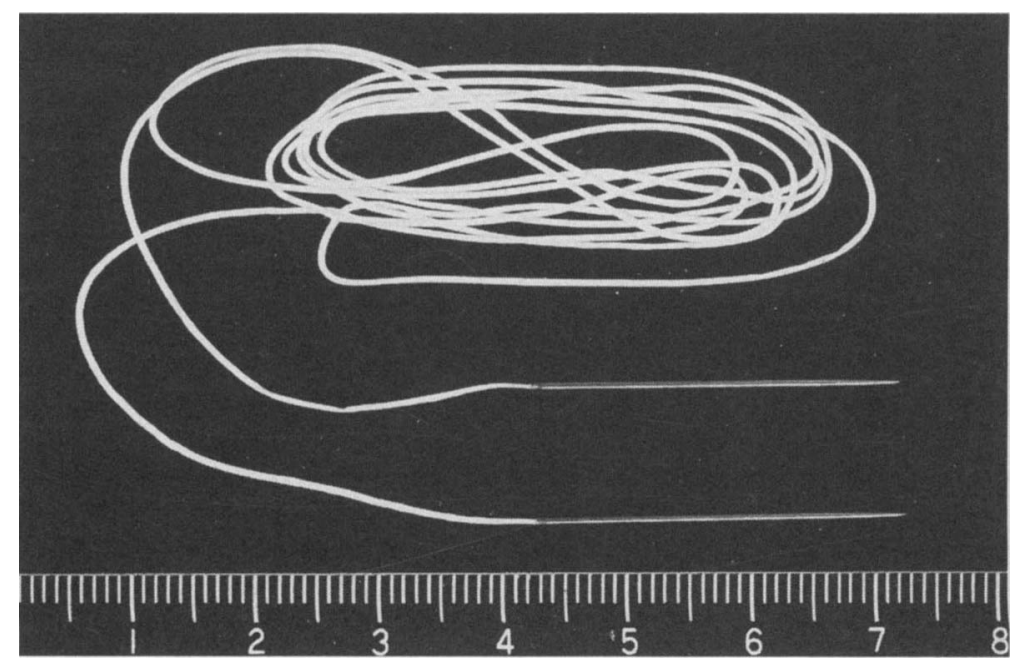

Fig. 1. Newly developed 3-0 expanded PTFE suture, having straight needles on both ends.

maintained with $0.8 \%$ halothane. The femoral artery was cannulated for monitoring of the systemic blood pressure and a central venous infusion catheter was inserted via the femoral vein. A probe for transesophageal echocardiography was inserted into the esophagus. A median sternotomy was then performed and the pericardium was opened and suspended. A left atrial catheter was inserted, and heart rate, systemic blood pressure, and left atrial pressures were measured as the control value. After an initial bolus dose of heparin $(3 \mathrm{mg} / \mathrm{kg})$ was administered, an arterial cannula was inserted into the ascending aorta and venous cannulas were inserted into the superior and inferior venae cavae through the right atrium. The dogs underwent total cardiopulmonary bypass at a flow rate of $100 \mathrm{ml} / \mathrm{kg}$ per minute without cooling. The following procedures were carried out on the normothermic beating hearts.

Specially developed 3-0 PTFE sutures, which have straight needles on both ends, were used in this experiment (Fig. 1). The left atrium was opened from the left appendage to its free wall and one major marginal chorda of the anterior mitral leaflet at the anterior commissure side was resected. The PTFE suture was attached to the anterior mitral leaflet at the origin of the removed chorda by a mattress suture. The needles, thereafter, were brought from the root of the anterior papillary muscle to the outside of the left ventricle and passed through a Dacron pledget for reinforcement (Fig. 2, $A$ ). After the left atrium was closed, the pump flow was reduced to $30 \mathrm{ml} / \mathrm{kg}$ per minute and the volume load rose until the left atrial pressure increased enough to get the systemic blood pressure equal to the prebypass pressure. For the control data of mitral incompetence, heart rate, systemic blood pressure, and left atrial pressure were measured, and transesophageal and epicardial echocardiography was performed to recognize prolapse of the anterior mitral leaflet and mitral regurgitation jet. Severity of mitral regurgitation was identified by means of a criterion developed by Stewart and colleagues. ${ }^{7}$ Both ends of the PTFE suture were gradually pulled until the length of the new PTFE chorda became ideal and valve competence was achieved, according to two-dimensional echocardiography and Doppler color flow mapping. At that point the suture was temporarily tied, and the animal was weaned from bypass (Fig. $2, B$ ). Then bypass was discontinued and protamine (heparin dose $\times 1.5$ ) was used to reverse the heparin. The valve competence was again confirmed with echocardiography, and the sutures were tied permanently. Hemodynamics were measured and echocardiography was performed to evaluate mitral valve function. The dogs were then killed and their gross anatomic findings were evaluated.

\section{Results}

The data of the hemodynamic study during the experiments are shown in Table I. Whereas the systemic blood pressure remained at almost the same level during the entire experiment, left atrial pressure severely increased after mitral regurgitation was created and markedly decreased after it was controlled with the PTFE suture. After regurgitation was created, the pressure of the v wave increased from 18 to $38 \mathrm{~mm} \mathrm{Hg}$, from 15 to $40 \mathrm{~mm}$ $\mathrm{Hg}$, and from 19 to $46 \mathrm{~mm} \mathrm{Hg}$ in $\operatorname{dog} 1$, dog 2, and dog 3 , respectively. After mitral regurgitation was controlled. the pressure of the $v$ wave remarkably decreased to 18.30 . and $24 \mathrm{~mm} \mathrm{Hg}$ in dogs 1, 2, and 3, respectively.

Intraoperative two-dimensional echocardiography showed that the anterior mitral leaflets were prolapsed before the optimal PTFE suture length was obtained. At that time, 4+ mitral regurgitation jets (severe) were also identified in all of the dogs with Doppler color flow mapping. After the chordal replacements with the PTFE suture were completed, the epicardial and transesophageal two-dimensional echocardiograms confirmed good competence of the mitral valves and good pliability of the anterior leaflets in all of the dogs. Doppler color flow mapping also showed $1+$ regurgitation jets (trivial) in all of the dogs. Intraoperative two-dimensional echocardiograms of $\operatorname{dog} 3$ are shown in Fig. 3. The epicardial color 


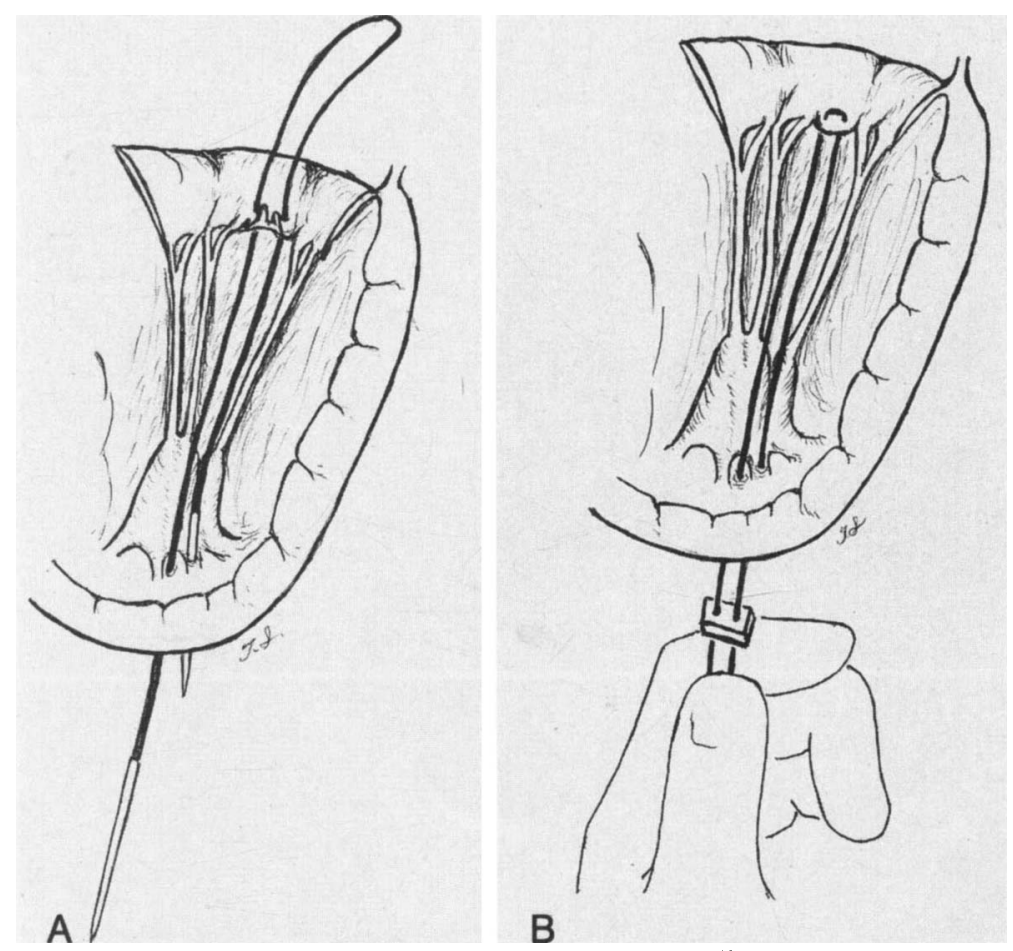

Fig. 2. A, One major marginal chorda of the anterior mitral leaflet was resected. The PTFE suture, which has straight needles on both ends, was attached to the anterior mitral leaflet by a mattress suture. The needles thereafter were brought from the root of the anterior papillary muscle to the outside of the left ventricle. $\mathbf{B}$, The needles passed through a Dacron pledget for reinforcement. After left atrial pressure increased enough to produce systemic blood pressure, both ends of the PTFE suture were gradually pulled until the length of the new PTFE chorda became ideal and valve competence was achieved, according to echocardiographic guidance. At that point the suture was temporarily tied.

Table I. Hemodynamic changes during experiments

\begin{tabular}{|c|c|c|c|c|c|c|c|c|c|}
\hline \multirow[b]{2}{*}{$\begin{array}{c}\text { Dog } \\
\text { No. }\end{array}$} & \multicolumn{3}{|c|}{ Before bypass } & \multicolumn{3}{|c|}{ During $M R$} & \multicolumn{3}{|c|}{ After control of $M R$} \\
\hline & $\begin{array}{c}H R \\
\text { (beats/min) }\end{array}$ & $\begin{array}{c}B P \\
(m m ~ H g)\end{array}$ & $\begin{array}{c}\overline{L A P} \\
(m m \mathrm{Hg})\end{array}$ & $\begin{array}{c}H R \\
\text { (beats/min) }\end{array}$ & $\begin{array}{c}B P \\
(m m H g)\end{array}$ & $\begin{array}{c}L A P \\
(m m H g)\end{array}$ & $\begin{array}{c}H R \\
\text { (beats } / \mathrm{min} \text { ) }\end{array}$ & $\begin{array}{c}B P \\
(m m \mathrm{Hg})\end{array}$ & $\begin{array}{c}L A P \\
(m m \mathrm{Hg})\end{array}$ \\
\hline 1 & 200 & $\begin{array}{c}124 / 100 \\
(110)\end{array}$ & $\begin{array}{c}16 / 18 \\
(14)\end{array}$ & 120 & $\begin{array}{c}120 / 90 \\
(106)\end{array}$ & $\begin{array}{c}34 / 38 \\
(36)\end{array}$ & 142 & $\begin{array}{c}120 / 90 \\
(108)\end{array}$ & $\begin{array}{c}19 / 18 \\
(17)\end{array}$ \\
\hline 2 & 162 & $\begin{array}{c}146 / 108 \\
(133)\end{array}$ & $\begin{array}{c}20 / 15 \\
(12)\end{array}$ & 156 & $\begin{array}{c}140 / 110 \\
(122)\end{array}$ & $\begin{array}{c}28 / 40 \\
(30)\end{array}$ & 174 & $\begin{array}{c}140 / 100 \\
(118)\end{array}$ & $\begin{array}{c}25 / 30 \\
(20)\end{array}$ \\
\hline 3 & 150 & $\begin{array}{c}138 / 105 \\
(125)\end{array}$ & $\begin{array}{c}22 / 19 \\
(14)\end{array}$ & 106 & $\begin{array}{c}130 / 100 \\
(118)\end{array}$ & $\begin{array}{c}40 / 46 \\
(42)\end{array}$ & 120 & $\begin{array}{c}135 / 105 \\
(115)\end{array}$ & $\begin{array}{c}27 / 24 \\
(20)\end{array}$ \\
\hline
\end{tabular}

$M R$. Mitral regurgitation: $H R$, heart rate; $B P$, blood pressure, systolic/diastolic (mean); $L A P$, left atrial pressure, a wave/v wave (mean).

Doppler flow maps of dog 1 are shown in Fig. 4, and the transesophageal color Doppler flow maps of $\operatorname{dog} 2$ are shown in Fig. 5.

Postmortem macroscopic examination of the three hearts revealed the length of the PTFE chordae to be suitable compared with the length of native chordae in the posterior medial commissure. No lacerations or bleeding areas were present in the left ventricular walls where the PTFE suture passed through. The postmortem gross findings of the heart in $\operatorname{dog} 2$ are shown in Fig. 6.

\section{Discussion}

Since Carpentier and associates ${ }^{8}$ reported an excellent 10 -year result of surgical repair for mitral valve incom- 

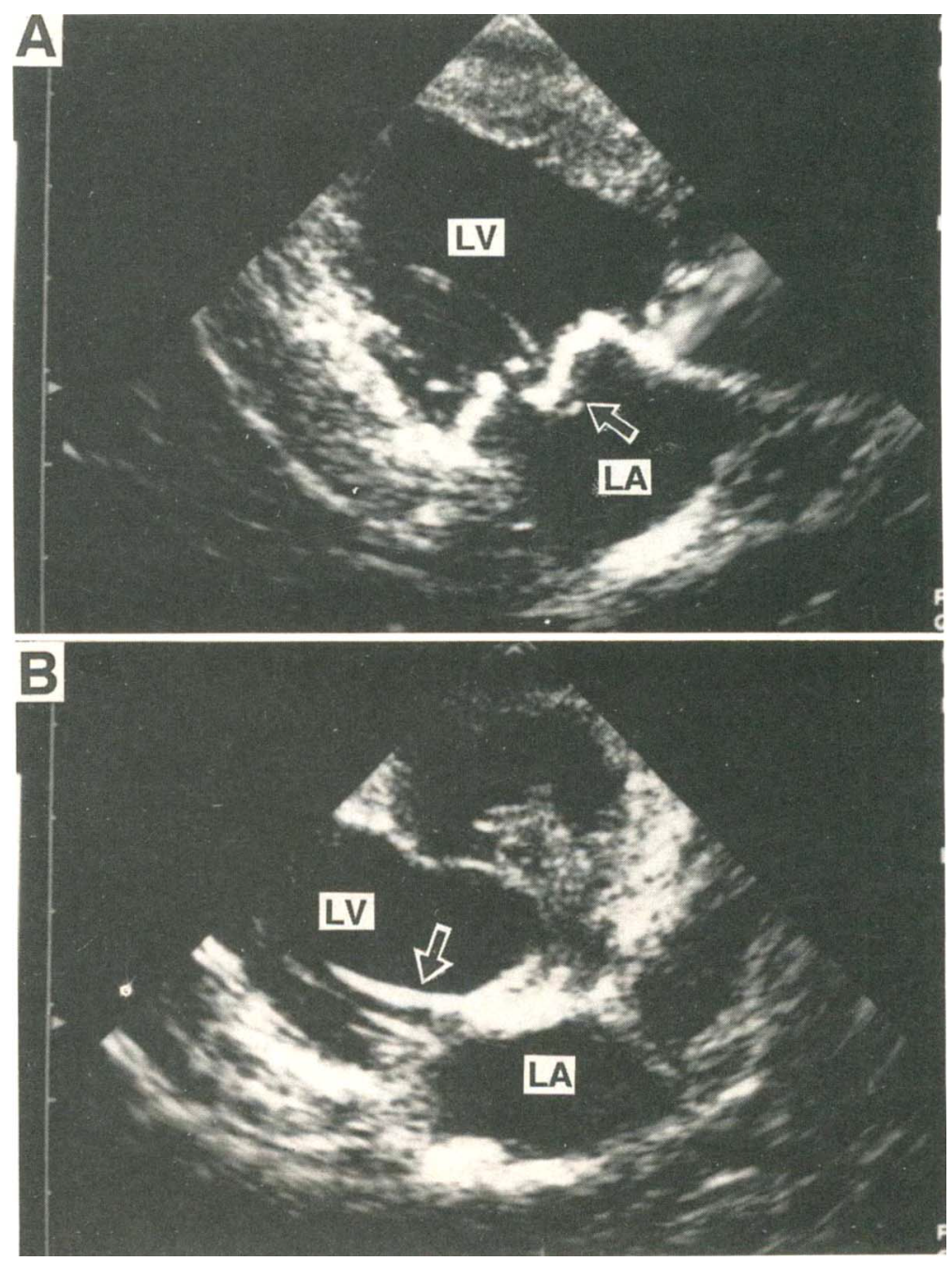

Fig. 3. Intraoperative epicardial two-dimensional echocardiographic images in systolic phases. A, Long-axis view after resection of a major chorda of the anterior mitral leaflet, demonstrating anterior mitral leaflet prolapse (arrow). B, Long-axis view after completion of the new tendon replacement technique, demonstrating normalized coaptation of the anterior mitral leaflet. The PTFE suture is identified (arrow). $L V$, Left ventricle; $L A$, left atrium.

petence, reconstructive surgery has been considered the first choice for mitral valve incompetence, especially that resulting from degenerative diseases. Many good clinical results of these operations have been reported..$^{9-13}$ The repair of mitral incompetence caused by prolapse of the posterior leaflet is simple and reproducible, but the surgical procedures for anterior leaflet prolapse are complex and still subject to challenge. In general, it appears that four major techniques, such as triangular resection of the anterior leaflet, chordal shortening, chordal transposition, and chordal replacement, are available for repairing anterior leaflet prolapse. Salati and associates ${ }^{12}$ reported their excellent surgical results of chordal transposition techniques and summarized some disadvantages of three other techniques: (1) Triangular resection may be effective only on small prolapses; (2) chordal shortening procedures have been considered too complex; and (3) chordal replacement with autologous or synthetic materials still lacks a systematic clinical evaluation, and the correct evaluation of the natural length is subjective and difficult in the totally relaxed heart. However, David and coworkers ${ }^{14}$ described the limitation of chordal transposition. Patients with prolapse of both leafiets may not have a suitable area of the posterior leaflet to anchor the prolapsing anterior leaflet.

Expanded PTFE sutures for replacement of mitral valve chordae tendineae were first introduced by Vetter, Frater, and their colleagues ${ }^{1}$ in 1986 . They reported that 

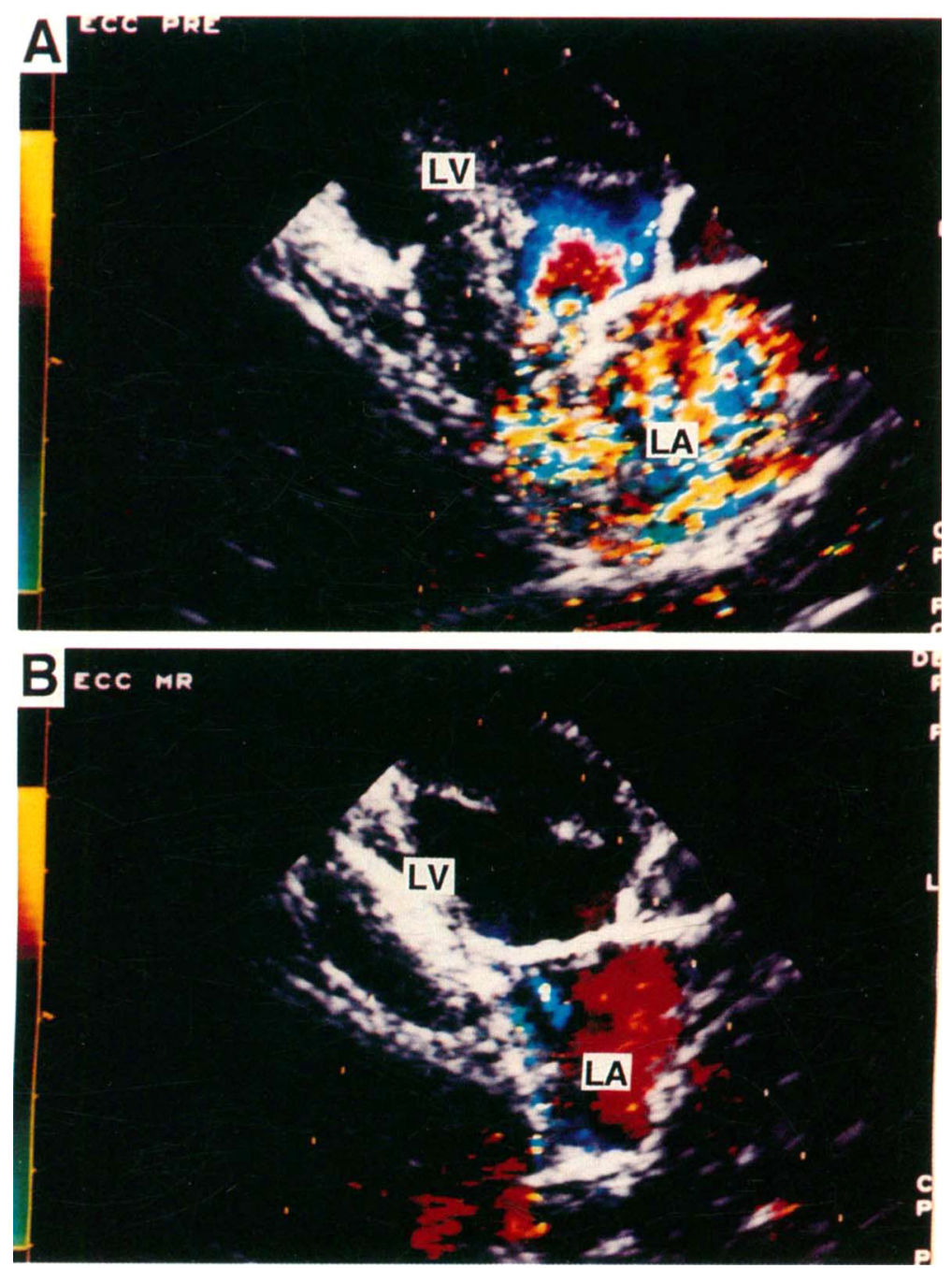

Fig. 4. Intraoperative epicardial Doppler color flow mapping images in systolic phases. A, Long-axis view after resection of a major chorda of the anterior mitral leaflet, demonstrating the $4+$ (severe) mitral regurgitation jet. $B$, Long-axis view after completion of the new chordal replacement technique, demonstrating the $1+($ trivial) regurgitation jet. $L V$, Left ventricle; $L A$, left atrium.

the morphologic appearance of the PTFE surface looked smooth with only a few filamentous fibers and no platelet accumulations by scanning electron microscopy in sheep surviving for 12 months. They also reported that no calcification or severe lack of flexibility was apparent in the sheep. Later, Revuelta and coworkers ${ }^{15}$ independently confirmed the durability of the PTFE sutures for 24 months in sheep models.

Recently, many good clinical results of chordal replacements with PTFE sutures have been reported. ${ }^{2-5}$ Frater and coworkers ${ }^{3}$ reported on 13 patients who had been followed up for 6 months to 4 years with a mean follow-up of 1.8 years. David, Bos, and Rakowski ${ }^{4}$ reported follow-up data on 43 patients extending from 5 to 61 months, mean 13 months. In our institute, the first patient underwent chordal replacement of the anterior leaflet with the PTFE suture in $1989,{ }^{16}$ and his mitral valve competence has been maintained for 4 years.

These clinical results indicate that the durability of PTFE suture is excellent. Replacement of chordae tendineae with PTFE sutures is becoming a procedure of choice for some surgeons. However, most surgeons still believe that the replacement of chorade tendineae is complicated. As Salati and associates ${ }^{12}$ suggest, the major problem for most surgeons is how to decide the optimal length of new tendons. Although Frater ${ }^{6}$ 

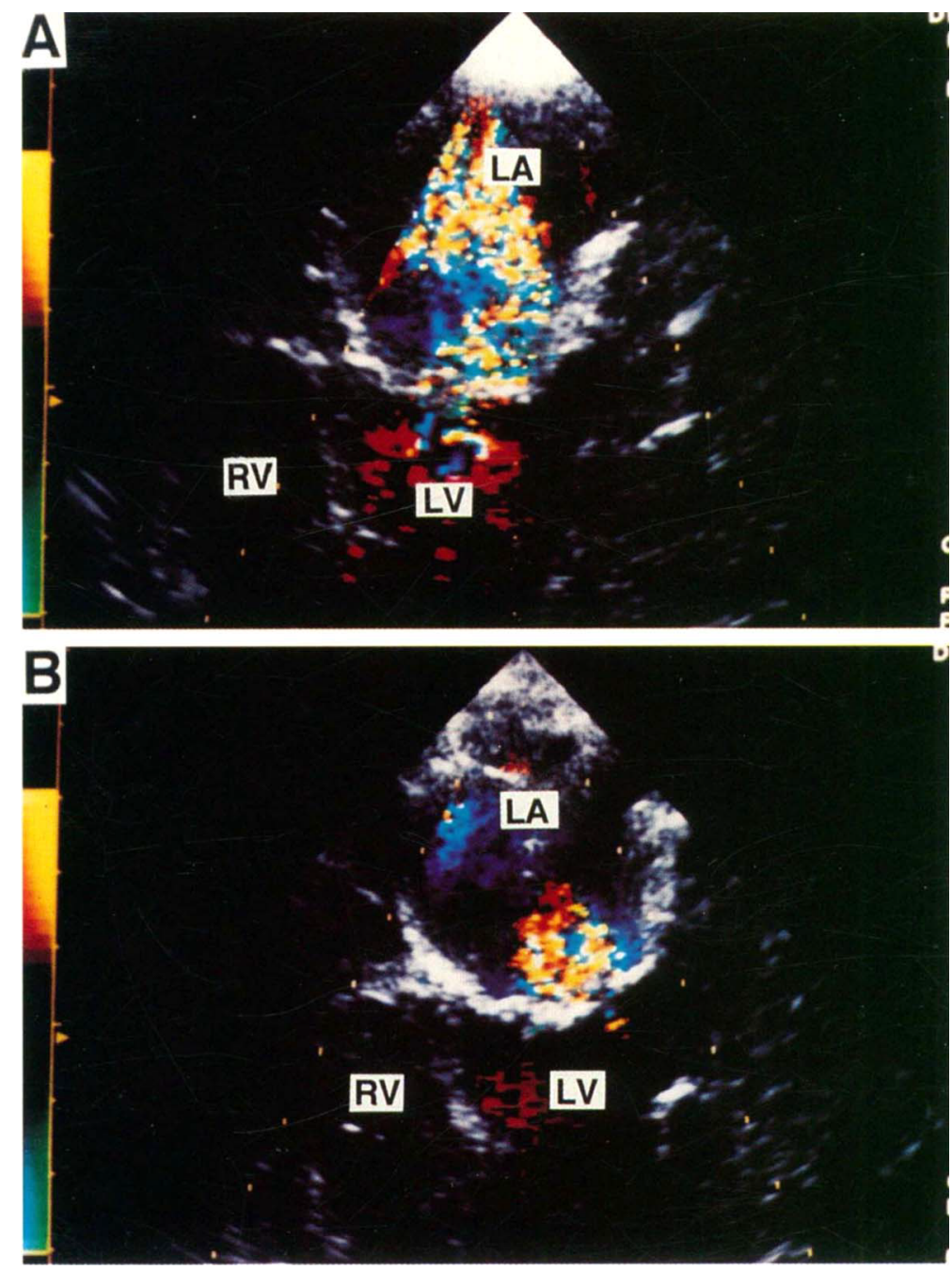

Fig. 5. Intraoperative transesophageal Doppler color flow mapping images in systolic phases. A, Transverse fourchamber view after resection of a major chorda of the anterior mitral leaflet, demonstrating the $4+$ (severe) mitral regurgitation jet. B, Transverse four-chamber view after completion of the new chordal replacement technique, demonstrating the $1+$ (trivial) regurgitation jet. $L A$, Left atrium; $R V$, right ventricle; $L V$, left ventricle.

described how to determine the exact length of new tendons, it appears difficult in patients in whom both leaflets are prolapsed and, therefore, the exact reference point of the posterior leaflet is lacking.

We tried to develop a new method of chordal replacement with this specially designed PTFE suture using intraoperative echocardiography. The essential point of our technique is that the length of the new chorda must be determined on the basis of functional evaluation of the mitral valve. In our technique, the length of the new PTFE chorda can be adjusted to achieve complete competence of the mitral valve according to two-dimensional echocardiography and Doppler color flow mapping. A technique reported by Revuelta and associates ${ }^{15}$ uses the same concept as our technique; in particular, the length of the chorda is based on valve function, not valve shape. However, the method of estimating valve function is different between Revulta's technique and our technique. In our technique, mitral valve function can be determined in the beating heart, and with enough dilatation and pressure of the left ventricle, whereas in Revulta's technique, the condition is the arresting heart and low pressure of the left ventricle.

In our new procedure, the concern was bleeding from an area where the PTFE suture penetrated the left ventricular wall. However, no bleeding was observed around 


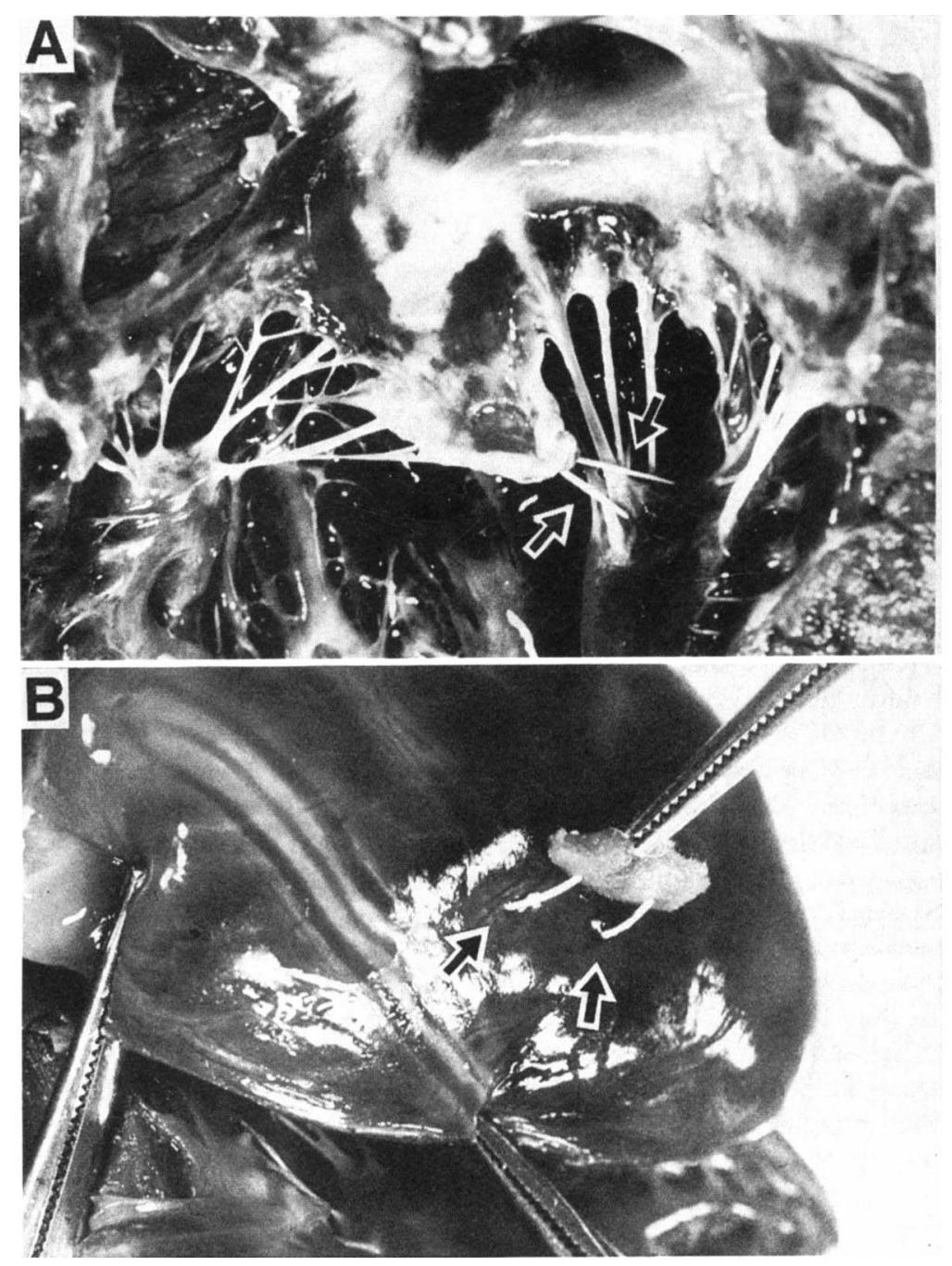

Fig. 6. Postmortem gross findings of the heart. A, No damage of the anterior leaflet is identified and the length of the PTFE chorda is suitable (arrows). B, No laceration of the left ventricular wall is observed at the site of the PTFE suture (arrows).

that area, perhaps because the dimension of the suture was larger than that of the needle. In this animal study, the intracardiac procedures, such as putting the PTFE suture in the leaflet and bringing it out the wall of the left ventricle, were performed with the heart beating because the purpose of this study is an acute phase and a preliminary evaluation of the new method of chordal replacement. Nevertheless, we believe that in patients those intracardiac procedures should be performed with the heart arrested to prevent air embolism.

We are concerned whether mitral valve competence can be maintained without papillary muscle. David's tendon replacement procedure can preserve papillary muscle function because the PTFE sutures are placed on the fibrous portions of the papillary muscle. However, in many cases of tendon replacement the PTFE suture are passed through the body of the papillary muscle, and in most cases of chordal shortening the papillary muscles are incised. The papillary muscle functions appear to be impaired in these procedures, but mitral valve competence can be maintained. In these procedures, it is not necessary to preserve the papillary muscle function for valve competence. In our procedure, therefore, mitral valve competence can be maintained without the papillary muscle.

Even though this study is a preliminary animal study, these results suggest great potential for our new chordal 
replacement technique. Our technique seems to be reproducible because intraoperative echocardiography is used to determine the optimal length of PTFE chordae.

We gratefully acknowledge Dr. Nosé, MD, PhD (Department of Surgery, Baylor College of Medicine) for his critical reviewing and Mrs. Julia A. Glueck for her assistance with English.

\section{REFER E N C ES}

1. Vetter HO, Burack JH, Factor SM, Macaluso F, Frater RWM. Replacement of chordae tendineae of the mitral valve using the new expanded PTFE suture in sheep. In: Bodnar E, Yacoub M, eds. Biologic bioprothetic valves. New York: Yorke Medical Books, 1986:772-84.

2. Zussa C, Frater RWM, Polesel E, Galloni M, Valfe C. Artificial mitral valve chordae: experimental and clinical experience. Ann Thorac Surg 1990;50:367-73.

3. Frater RWM, Vetter HO, Zussa C, Dahm M. Chordal replacement in mitral valve repair. Circulation 1990;82 (Suppl):IV125-30.

4. David TE, Bos J, Rakowski H. Mitral valve repair by replacement of chordae tendineae with polytetrafluoroethylene sutures. J Thorac Cardiovasc Surg 1991;101: 495-501.

5. Kawazoe K, Eishi K, Sasako Y, et al. Clinical experience of mitral valve reconstruction with artificial chorda implantation. Eur J Cardiothorac Surg 1992;6:297-301.

6. Frater RWM. J Cardiac Surg 1990;5:152-3 (Letter).

7. Stewart WJ, Currie PJ, Salcedo EE, et al. Intraoperative Doppler color flow mapping for decision-making in valve repair for mitral regurgitation: technique and results in 100 patients. Circulation 1990;81:556-66.
8. Carpentier A, Chauvaud S, Fabiani JN, et al. Reconstructive surgery of mitral valve incompetence: ten-year appraisal. J Thorac Cardiovasc Surg 1980;79:338-48.

9. Galloway AC, Colvin SB, Bauman FG, et al. A comparison of mitral valve reconstruction with mitral valve replacement: intermediate-term results. Ann Thorac Surg 1989; 47:655-62.

10. Lessan A, Carbone C, Romano M, et al. Mitral valve repair: results and decision-making process in reconstruction report of 275 cases. J THORAC CARdiovasC SurG 1990;99:622-30.

11. Deloche A, Jebara VA, Relland J, et al. Valve repair with Carpentier techniques: the second decade. J THORAC CARDIOVASC SURG 1990;99:990-1002.

12. Salati M, Scofani R, Fundaró P, Cialfi A, Santoli C. Correction of anterior mitral prolapse: results of chordal transposition. J THORAC CARDIOVASC SURG 1992;104:1268-73

13. David TE, Armstrong S, Sun Z, Daniel L. Late results of mitral valve repair for mitral regurgitation due to degenerative disease. Ann Thorac Surg 1993;56:7-14.

14. David TE. Invited letter concerning: Correction of prolapse of the anterior leaflet of the mitral valve. J THORAC CARDIOVASC SuRG 1992;104:1489.

15. Revuelta JM, Garcia-Rinadli R, Gaite L, Val F, Garijo F. Generation of chordae tendineae with polytetrafluoroethylene stents: results of mitral valve chordal replacement in sheep. J THORAC CaRdiovasc SuRg 1989;97:98-103.

16. Yada I, Mizumoto T, Sato T, Wada K, Simono T, Kusagawa $M$. A case report on the repair of an anterior mitral leaflet chordal rupture using PTFE suture. Nippon Kyobu Geka Gakkai Zasshi 1990;38:2330-5 [English Abstract]. 